\title{
Longitudinal associations in adolescence between cortisol and persistent aggressive or rule-breaking behavior
}

\author{
Evelien Platje $^{\mathrm{a}, *}$, Lucres M.C. Jansen ${ }^{\mathrm{a}}$, Adrian Raine ${ }^{\mathrm{b}}$, Susan J.T. Branje ${ }^{\mathrm{c}}$, Theo A.H. Doreleijers ${ }^{\mathrm{a}, \mathrm{d}}$, \\ Marjan de Vries-Bouw ${ }^{a}$, Arne Popma ${ }^{a}$, Pol A.C. van Lier ${ }^{e}$, Hans M. Koot $^{\mathrm{e}}$, \\ Wim H.J. Meeus ${ }^{c}$, Robert R.J.M. Vermeiren ${ }^{\mathrm{a}, \mathrm{f}}$ \\ a VU University Medical Center, Department of Child and Adolescent Psychiatry, PO Box 303, 1115 ZG Duivendrecht, The Netherlands \\ ${ }^{\mathrm{b}}$ Departments of Criminology, Psychiatry, and Psychology, Jerry Lee Center of Criminology, University of Pennsylvania, 3809 Walnut Street, Philadelphia, PA 19104, USA \\ ${ }^{\mathrm{c}}$ Utrecht University, Research Center Adolescent Development, Heidelberglaan 2, Van Unnik Gebouw, 3584 CS Utrecht, The Netherlands \\ d Leiden University, Department of Criminal Law and Criminology, PO Box 9520, 2300 RA Leiden, The Netherlands \\ e VU University, Department of Developmental Psychology, Van der Boechorststraat 1, 1081 BT Amsterdam, The Netherlands \\ f Curium-Leiden University Medical Center, PO Box 15, 2300 AA Leiden, The Netherlands
}

\section{A R T I C L E I N F O}

\section{Article history:}

Received 15 August 2012

Accepted 14 January 2013

Available online 21 January 2013

\section{Keywords:}

Antisocial behavior

Aggression

Cortisol

Hypothalamic-pituitary-adrenal axis

Adolescence

Longitudinal

\begin{abstract}
A B S T R A C T
Although several studies have associated antisocial behavior with decreased cortisol awakening responses (CAR), studies in adolescent samples yielded inconsistent results. In adolescence however, the CAR develops and antisocial behavior is heterogeneous in type and persistence. Therefore this longitudinal study compared persistent aggressive and rule-breaking adolescents to low aggressive and rule-breaking adolescents on the development of the CAR from ages 15 to $17(N=390)$. Persistently high aggressive adolescents showed decreased cortisol levels at awakening consistently over the years $\left(\Delta \chi^{2}(1)=6.655, p=.01\right)$ as compared to low aggressive adolescents. No differences between adolescents showing persistent high rule-breaking and low rule-breaking were found. This longitudinal study is the first to show that persistent aggression, but not rule-breaking behavior, is related to neurobiological alterations. Moreover, despite development of the CAR over adolescence, the decrease in cortisol is consistent over time in persistent high aggressive adolescents, which is an important prerequisite for the prediction of persistent aggression.
\end{abstract}

(c) 2013 Elsevier B.V. All rights reserved.

\section{Introduction}

Antisocial behavior has often been associated with decreased hypothalamic-pituitary-adrenal (HPA) axis activity (van Goozen et al., 2007). Especially studies in children show consistent associations between decreased HPA axis activity and antisocial behavior (Alink et al., 2008), as do the few studies in adult samples (King et al., 1990; Virkkunen, 1985; Woodman et al., 1978). Studies in adolescent samples, however, yielded inconsistent results (Alink et al., 2008; Popma et al., 2007; Sondeijker et al., 2007). As adolescence is a period of biological and behavioral change and development, the inconsistent results may be explained by adolescence specific changes in HPA axis activity and heterogeneity in antisocial behavior. In order to capture these changes, longitudinal studies are warranted. Therefore, the present longitudinal study focused on

\footnotetext{
* Corresponding author. Tel.: +31 20890 1545; fax: +31 207745690

E-mail address: e.platje@debascule.com (E. Platje).
}

changes in HPA axis activity and trajectories of antisocial behavior in adolescence.

In typically developing children the level of HPA axis activity increases over the years during adolescence (Gunnar and Vazquez, 2006). An often used measure of HPA axis activity, the cortisol awakening response (CAR), has also been shown to develop during adolescence (Platje et al., 2013), that is, the rise in cortisol levels as a response to awakening, increases from age 15 to 17. This development appears to be specific for adolescence, as it is associated with physical development characteristic for adolescence (Kiess et al., 1995; Platje et al., 2013; Rosmalen et al., 2005). Gunnar and Vazques further pointed out that these adolescence related changes in HPA axis activity have not been found in various clinical samples, such as depressive or anxious individuals. These developmental changes in HPA axis activity may also be absent for antisocial adolescents, yet to date, this has remained uninvestigated.

Antisocial behavior in adolescence is characterized by heterogeneity, and relationships with neurobiological parameters as the CAR, may vary by the persistence and type of antisocial behavior (Alink et al., 2008; Moffitt, 1993; Stadler et al., 2010). In adolescence 
the prevalence of antisocial behavior peaks, yet most antisocial behavior is limited to this developmental period. Merely a small subgroup displays persistent antisocial behavior, beyond the period of adolescence. It is only this small subgroup that is thought to carry neurobiological deficits (Moffitt, 1993; Raine et al., 2005). Especially in adolescence, the large majority of antisocial behavior is therefore most likely unrelated to the CAR. With respect to the type of behavior, aggression and rule-breaking are two main types often recognized within antisocial behavior (Achenbach et al., 1989; Burt, 2012; Loeber and Schmaling, 1985). These types show distinct developmental trajectories (Burt, 2012). Whereas rule-breaking peaks in adolescence, aggression occurs most frequently in childhood, and decreases from early adolescence onwards (Tremblay, 2010). Yet those who are most aggressive as children tend to be aggressive persistently into adulthood (Lahey et al., 2003). Burt therefore hypothesizes that aggression may be more persistent, whereas rule-breaking may be mainly limited to adolescence. More importantly, the relative influence of risk factors for aggression and rule-breaking differs as well. Both types are thought to result from complex interactions between environmental, social, cognitive, and biological risk factors (Moffitt, 1993; Raine et al., 2005). However, neurobiological deficits may be more strongly related to aggression than to rule-breaking (Burt, 2012; McBurnett et al., 2000).

The behavioral heterogeneity with respect to persistence and type of adolescent antisocial behavior, as well as the development of the CAR in adolescence, may explain the previously found inconsistent associations. Longitudinal studies on the CAR and antisocial behavior are, however, surprisingly sparse. Two studies repeatedly assessed both antisocial behavior and cortisol in a single sample, either during the day (McBurnett et al., 2000) or at awakening (Shirtcliff et al., 2005). These studies indicated that consistently low cortisol is related to aggression (McBurnett et al., 2000), and to risky behavior, mostly resembling rule-breaking (Shirtcliff et al., 2005) in preadolescent boys. As aggression and rule-breaking are largely overlapping behaviors within individuals (Loeber and Schmaling, 1985), it remains unclear whether low cortisol levels are indeed more strongly related to aggression than to rule-breaking. As for persistence, McBurnett et al. did find stronger relations with low cortisol for those persistently aggressive than for those aggressive at one time point. The CAR specifically was assessed by merely one predictive study, and only measured once in preadolescence (Sondeijker et al., 2008). A low CAR in preadolescence was found to predict persistent antisocial behavior in boys and girls (Sondeijker et al., 2008).

Change and development over adolescence of aggression and rule-breaking, as well as the CAR, have to date not been investigated in concert. The aim of the present study therefore was to investigate whether the development of the CAR over adolescence (ages 15, 16 and 17 years) differs by the persistence of aggression and rule-breaking over these years. Therefore, trajectories were identified based on the 2-year persistence of aggression and rule-breaking during adolescence. These trajectories were compared on the development of the CAR over adolescence. The levels of the CAR were expected to increase over the years with adolescence in those showing a trajectory of low aggressive and low rule-breaking behavior (Gunnar and Vazquez, 2006; Platje et al., 2013). Adolescents showing a trajectory of persistent rule-breaking were expected to resemble those showing low rule-breaking behavior (Burt, 2012), and also to show similar CAR levels over the years with adolescence. For persistent aggressive adolescents the CAR levels were expected to be decreased compared to low aggressive adolescents. Also, the increase of the CAR levels over adolescence may not be present in adolescents showing a trajectory of persistent aggression (Gunnar and Vazquez, 2006).

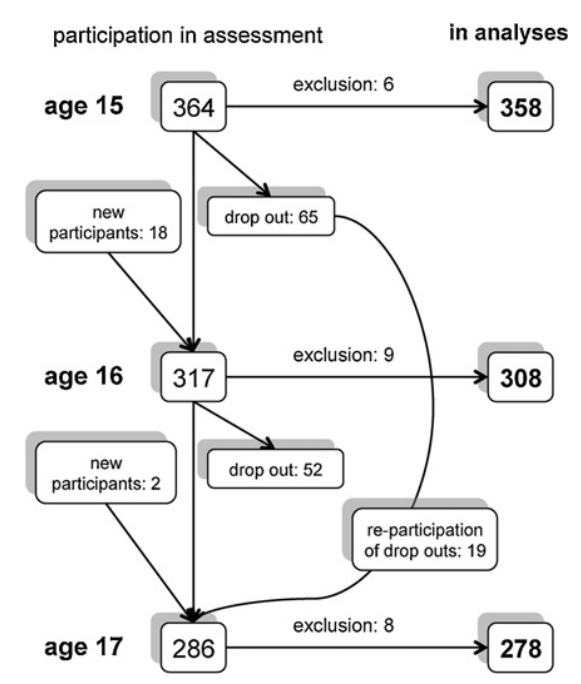

Fig. 1. Flow chart of participation at age 15, 16 and 17. Participation in the cortisol measurements at any age was $n=416$ adolescents, after exclusion on the basis of sampling errors, technical problems in the lab, or statistical outliers, 390 adolescents participated in the analyses. At each age, participants provided three saliva samples.

\section{Materials and methods}

\subsection{Participants and procedure}

Participants were 390 adolescents (222 boys and 168 girls) who took part in three annual assessments; at ages 15, 16 and 17 years. They were recruited from the RADAR (research on adolescent development and relationships) study. RADAR is a Dutch population based cohort study on adolescent relationships with family members and friends and the development of antisocial behavior, substance use and psychopathology. All participants and their parents have provided written informed consent and the RADAR study has been approved by the responsible medical ethics committee. This study is based on data from the third (2008) to the fifth wave (2010) of RADAR, in this paper referred to as ages 15-17.

Young adolescents at the final year of elementary school were screened and selected to participate by means of the teacher's report form (TRF; Achenbach, 1991a). Because antisocial development was one of the main outcome variables in the study, boys and girls with a borderline clinical score on the TRF externalizing scale $(T$-score $\geq 60)$ were over-sampled $(50 \%)$ in the study at age 11 . The total cohort consisted of 497 adolescents. Participants were visited at home by a trained researcher, who administered the behavioral measurements to the adolescents. During the home visit detailed verbal and written information regarding cortisol measurements was provided.

Of the total RADAR cohort, 416 adolescents (84\%) participated in the cortisol measurements at any year. Participants in the cortisol measurements were more often smokers than non-participants $\left(16.1 \%\right.$ vs. $3.7 \%$ at age $15, \chi^{2}=8.618, p=.002$; $25.0 \%$ vs. $11.1 \%$ at age $\left.17, \chi^{2}=7.445, p=.006\right)$. There was no difference in age, gender, pubertal status, BMI, or alcohol use (all $p>.1$ ) between those who did and those who did not participate in the cortisol measurements. As can be seen in Fig. 1, the number of participants fluctuated per year. Of the 416 adolescents participating in the cortisol measurements at any year, 390 adolescents participated in the analyses after exclusion on the basis of sampling errors, technical problems in the lab, or statistical outliers (see below). Drop-out was not associated with age, gender, BMI, or alcohol use (all $p>.1$ ), but drop-outs at age 16 were more often smokers $(26.2 \%$ vs. $\left.13.7 \%, \chi^{2}=6.170, p=.023\right)$.

\subsection{Aggression and rule-breaking trajectories}

Antisocial behavior was assessed by means of the externalizing scales of the youth self report (YSR; Achenbach, 1991b), administered to the adolescents. Within the externalizing dimension, sub-scales differentiate aggression and rule-breaking behavior. Items are scored on a three-point scale $(0=$ not true, $1=$ somewhat true, 2 = very true or often true). Scores were transformed to $T$-scores, which are normalized standard scores based on gender and age. Good reliability and validity have been reported for the Dutch YSR version (Verhulst et al., 1997).

In order to identify subgroups of adolescents with different mean-level trajectories of respectively aggression or rule-breaking from ages 15 to 17 , latent class growth analysis was used (LCGA; Nagin, 2005), with a linear growth model (growth parameters 0,1 , and 2). Variances, co-variances and variances of the indicators were set at respectively 0,0 and estimated free. Criteria to determine the number of groups were as follows. Adding a subgroup should improve the model fit as indicated by a decrease in the sample size adjusted bayesian information criterion (SSA BIC) and 
a significant $p$-value for the adjusted Lo, Mendell, and Rubin likelihood ratio test (adj. LMR-LRT). Entropy, a standardized measure of classification quality, should be .75 or higher. If an additional subgroup was found to be a slight variation of a subgroup already found in a lower class solution, the most parsimonious model was selected. Also, every subgroup had to cover at least $5 \%$ of the sample for meaningful interpretation and further analysis.

The LCGA resulted in two subgroups of trajectories for both behaviors. ${ }^{1}$ Adding a third subgroup resulted in non-significant Lo-Mendell-Rubin adjusted LRT tests. ${ }^{2}$ Both for aggression and rule-breaking, one trajectory was identified showing low levels of antisocial behavior from ages 15 to 17, these trajectories are labeled respectively low aggression and low rule-breaking. The other trajectories consisted of persistently high antisocial behavior from ages 15 to 17 , these are labeled respectively high aggression and high rule-breaking. The low aggressive and low rule-breaking trajectories showed similar levels of antisocial behavior, with mean scores just above the minimum score on the YSR (see Table 1). On aggressive behavior, 64 adolescents showed persistently high aggression, with mean $T$-scores largely in the borderline-clinical range of the YSR. Aggressive behavior decreased slightly over time $(\beta=-2.198, p=.019)$ for this trajectory. On rule-breaking behavior, 79 adolescents showed persistently high rule-breaking, although mean $T$-scores on all years fell within the normal range of the YSR. Of the 64 highly aggressive adolescents, 38 also showed high levels of rule-breaking behavior.

\subsection{Control variables}

As physical development and substance use are related to the development of the CAR (Platje et al., 2013) and may be associated with antisocial behavior, we took these variables into account in the analyses.

Physical development was assessed as pubertal development and the body mass index. Pubertal development was assessed at ages 15 and 16. It was measured by a modification of the pubertal development scale (PDS; Petersen et al., 1988), consisting of seven questions regarding physical development, i.e. growth spurt, axillary hair, pubarche, menarche, thelarche, voice change and facial hair. The possible range of the mean scores was $0.9-4.4$. Next, $Z$-scores were calculated separately for boys and girls, to indicate the individual pubertal development compared to the whole sample. The body mass index was calculated as weight in $\mathrm{kg} /(\text { length in } \mathrm{m})^{2}$.

Substance use was assessed as nicotine and alcohol use (Monshouwer et al., 2008). Alcohol use over the last 4 weeks was assessed by means of a six-option question, ranging from "none" to "daily". Nicotine use was assessed by a nine-option question ranging from "I have never smoked" to "I smoke every day".

\subsection{Cortisol assessment}

Cortisol was measured in saliva. Saliva samples were collected by passive drooling, immediately after awakening (Cort0), and $30 \mathrm{~min}$ (Cort30) and $60 \mathrm{~min}$ (Cort60) later. These three samples constitute the cortisol awakening response (CAR; Pruessner et al., 1997). Cortisol sampling took place in February and March of each consecutive year, as soon as possible after assessing aggression and rule-breaking. Participants were first given detailed verbal and written information regarding cortisol measurements. Subsequently, saliva sampling was planned for a suitable morning on a regular weekday. The first sample (at awakening) was planned before 8 a.m., while taking into consideration the participant's normal schedule. Sampling times were set and written on a detailed instruction form.

Participants were instructed to rinse their mouths with water before sampling, and not to eat, drink milk or juice, smoke or brush their teeth before completing Cort60. They were requested to report the exact sampling times on the instruction form on the day of sampling, and also to report if mistakes were made in any of the above instructions. After collection, participants were asked to store the samples in the refrigerator and send them by mail to the research center the same day.

At the research center, all samples were checked for correctness of sampling. When necessary, e.g. when Cort0 was sampled after 8:00 a.m. or sampling time of Cort30 or Cort60 was over $15 \mathrm{~min}$ late, or mistakes were made in any of the other instructions, participants were asked to collect new saliva samples, and a new sampling day was scheduled. If, despite this, participants had still not sampled correctly, the incorrect samples were excluded. In total 39 samples were excluded for incorrect sampling, and a total of 2853 samples was available for cortisol analysis.

Saliva was stored uncentrifuged at $-20^{\circ} \mathrm{C}$ until analysis. Salivary cortisol levels were analyzed using electrochemiluminescence immunoassay ECLIA (E170 Roche, Switzerland). The lower detection limit was $0.5 \mathrm{nmol} / \mathrm{l}$, and mean intra-assay and inter-assay coefficients of variation were respectively $3.4 \%$ and $12.2 \%$. Due to technical problems in the lab, 133 samples could not be assayed.

1 Model fit for aggression: SSA BIC $=7327.374$, LMR adj. LRT test $=440.108$, $p=0.0161$, entropy $=0.940$. Model fit for rule-breaking: SSA BIC $=6415.583$, LMR adj. LRT test $=361.795, \mathrm{p}=0.0082$, entropy $=0.911$.

2 Adj. LMR-LRT for aggression: 126.713, $\mathrm{p}=.35$ and for rule-breaking: 87.634, $\mathrm{p}=.54$.

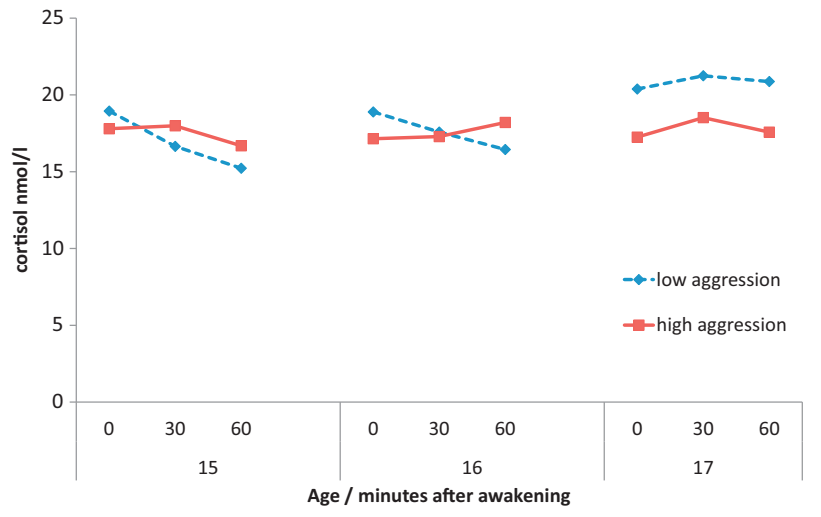

Fig. 2. Cortisol awakening response over adolescence for trajectories of high and low aggression.

\subsection{Statistical analyses}

Cortisol values over 3SD above the mean were defined as outliers and excluded (28 samples). After this, 2692 samples from 390 participants remained available for statistical analyses.

To estimate the pattern of missing values, Little's (1988) missing completely at random (MCAR) test was conducted. Although this very stringent test was significant $\left(\chi^{2}(411)=649.54, p<.001\right)$, the $\chi^{2} / \mathrm{df}$ ratio of 1.58 indicated a good fit between sample scores with and without imputation (Bollen, 1989).

Differences between the subgroups of aggression and rule-breaking in changes in the CAR from ages 15-17, were examined using multi-group multivariate latent growth modeling (LGM; Kline, 2005) within Mplus 6.0 (Muthén and Muthén, 2007) with maximum likelihood estimation (Satorra and Bentler, 1994). Mean-levels of Cort0, Cort30 and Cort60 at each year were used as indicators to estimate the latent intercepts (i.e. mean-level of the CAR) and slopes (i.e. mean change in the CAR over time) in LGM. The intercepts of Cort0, Cort30 and Cort60 the CAR were allowed to correlate. In LGM, individual differences in change trajectories are captured by including variances for the latent growth parameters (i.e. the intercept and slope variance). Using chi-square difference tests, we examined whether intercepts and slopes of the CAR varied across the subgroups of aggression and rule-breaking. We evaluated fit of the growth models using several goodness-of-fit indices (Kline, 2005): the comparative fit index (CFI) and the root mean square error of approximation (RMSEA).

As gender and physical development appeared to be equally distributed among the subgroups, but substance use differed between the subgroups, we examined whether potential differences between the subgroups in the development of the CAR would be due to substance use. Hence, in the final model we regressed the observed measures of the CAR per year on alcohol and nicotine use, assessed in the same year.

\section{Results}

In Fig. 2 the development of the CAR from ages 15 to 17 is shown for high and low aggressive adolescents. When testing overall differences in the CAR from ages 15 to 17 , high aggressive adolescents show significantly different cortisol levels and changes over time, compared to low aggressive adolescents $\left(\Delta \chi^{2}(6)=16.33\right.$, $p=.01)$. Post hoc tests revealed that these differences were significant for cortisol levels (i.e. intercepts) at awakening only: high aggressive adolescents had decreased levels of awakening cortisol over the 3 years, compared to low aggressive adolescents $\left(\Delta \chi^{2}(1)=6.66, p=.01\right)$. The cortisol levels at 30 and $60 \mathrm{~min}$ did not differ between high and low aggressive adolescents $\left(\Delta \chi^{2}(1)=0.20\right.$, $p=.66$ for Cort30 and $\Delta \chi^{2}(1)=0.21, p=.65$ for Cort60). The development of cortisol levels (i.e. the increase/slope over the years) did not differ between high and low aggressive adolescents either $\left(\Delta \chi^{2}(1)=1.80, p=.18\right.$ for Cort0; $\Delta \chi^{2}(1)=0.82, p=.37$ for Cort30; and $\Delta \chi^{2}(1)=0.34, p=.56$ for Cort60).

In Fig. 3 the development of the CAR from ages 15 to 17 is shown for high and low rule-breaking adolescents. For the rule-breaking subgroups, the overall development (i.e. levels and changes) of the CAR from ages 15 to 17 did not differ significantly between high and low rule-breaking adolescents $\left(\chi^{2}(6)=4.755, p=.58\right.$, see also Fig. 3$)$. 
Table 1

Descriptive statistics per trajectory of aggression and rule-breaking.

\begin{tabular}{|c|c|c|c|c|c|c|}
\hline & \multicolumn{3}{|l|}{ Aggression } & \multicolumn{3}{|l|}{ Rule-breaking } \\
\hline & Low $(n=326)$ & $\operatorname{High}(n=64)$ & $t / \chi^{2}$ test & Low $(n=311)$ & High $(n=79)$ & $t / \chi^{2}$ test \\
\hline \multicolumn{7}{|l|}{ Antisocial behavior } \\
\hline Age 15 & $52.28(4.02)$ & $68.78(7.77)$ & $t(68.591)=16.42^{* * *}$ & $51.44(2.25)$ & $60.68(4.63)$ & $t(86.403)=17.13^{* * *}$ \\
\hline Age 16 & $52.38(3.96)$ & $65.73(8.61)$ & $t(66.134)=11.96^{* * *}$ & $52.20(2.98)$ & $60.57(5.10)$ & $t(89.606)=13.81^{* * *}$ \\
\hline Age 17 & $52.39(4.48)$ & $64.50(10.44)$ & $t(63.275)=8.83^{* * *}$ & $52.71(3.48)$ & $59.11(5.59)$ & $t(87.685)=9.406^{* * *}$ \\
\hline Gender (\% boys) & $55.5 \%$ & $64.1 \%$ & $\chi^{2}(1)=1.592$ & $57.2 \%$ & $55.7 \%$ & $\chi^{2}(1)=0.06$ \\
\hline Age $^{\mathrm{a}}$ & $15.03(0.45)$ & $15.02(0.47)$ & $t(388)=0.124$ & $15.02(0.46)$ & $15.06(0.41)$ & $t(388)=0.77$ \\
\hline \multicolumn{7}{|l|}{ Pubertal status } \\
\hline Age 15 & $3.26(0.79)$ & $3.12(0.75)$ & $t(385)=-1.287$ & $3.21(0.80)$ & $3.33(0.71)$ & $t(385)=1.15$ \\
\hline Age 16 & $3.62(0.66)$ & $3.60(0.75)$ & $t(377)=-0.316$ & $3.60(0.67)$ & $3.71(0.69)$ & $t(377)=1.38$ \\
\hline \multicolumn{7}{|l|}{ BMI } \\
\hline Age 15 & $20.00(2.81)$ & $20.46(4.03)$ & $t(382)=-1.097$ & $19.93(2.78)$ & $20.65(3.84)$ & $t(382)=1.89$ \\
\hline Age 16 & $20.65(2.55)$ & $20.81(3.10)$ & $t(372)=0.431$ & $20.59(2.57)$ & $20.99(2.89)$ & $t(372)=1.18$ \\
\hline Age 17 & $22.13(3.28)$ & $22.53(4.07)$ & $t(315)=0.765$ & $22.24(3.33)$ & $22.06(3.78)$ & $t(315)=-0.38$ \\
\hline \multicolumn{7}{|l|}{ Alcohol use $\mathrm{b}^{\mathrm{b}}$} \\
\hline Age 15 & $48.3 \%$ & $63.5 \%$ & $\chi^{2}(1)=4.872^{*}$ & $44.1 \%$ & $76.9 \%$ & $\chi^{2}(1)=26.76^{* * *}$ \\
\hline Age 16 & $72.7 \%$ & $85.2 \%$ & $\chi^{2}(1)=4.272$ & $71.5 \%$ & $87.0 \%$ & $\chi^{2}(1)=7.76^{* *}$ \\
\hline Age 17 & $84.6 \%$ & $91.7 \%$ & $\chi^{2}(1)=2.032$ & $84.2 \%$ & $91.9 \%$ & $\chi^{2}(1)=2.83$ \\
\hline \multicolumn{7}{|l|}{ Nicotine use ${ }^{b}$} \\
\hline Age 15 & $14.4 \%$ & $25.0 \%$ & $\chi^{2}(1)=4.424^{* *}$ & $10.9 \%$ & $36.7 \%$ & $\chi^{2}(1)=30.90^{* * *}$ \\
\hline Age 16 & $19.0 \%$ & $35.9 \%$ & $\chi^{2}(1)=8.985^{*}$ & $14.5 \%$ & $50.6 \%$ & $\chi^{2}(1)=48.34^{* * *}$ \\
\hline Age 17 & $23.6 \%$ & $37.5 \%$ & $\chi^{2}(1)=5.371^{*}$ & $18.6 \%$ & $54.4 \%$ & $\chi^{2}(1)=42.03^{* * *}$ \\
\hline
\end{tabular}

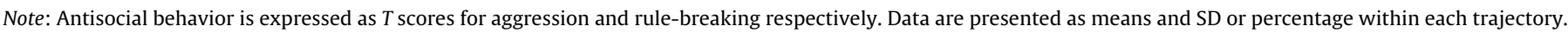

a Age at the first assessment (age 15).

b Dichotomized values (percentage of use) are presented, continuous measures of substance use were used in the analyses.

${ }^{*} p<.05$.

*** $p<.01$.

*** $p<.001$.

Substance use has been associated with an increased development of the CAR (Platje et al., 2013), and is also more prevalent in the high compared to the low antisocial trajectories (Table 1). We therefore examined whether differences between the trajectories in the development of the CAR could be explained by substance use, by adding substance use as a time-varying covariate. Controlling for substance use did not change the development of the CAR for the aggressive trajectories. Both the overall development (i.e. levels and changes) in the CAR $\left(\chi^{2}(6)=15.729, p<.05\right)$ as well as the cortisol levels at awakening, remained lower for the high aggressive adolescents compared to the low aggressive adolescents $\left(\chi^{2}(1)=7.086\right.$, $p=.01)$.

\section{Discussion}

The aim of the present study was to investigate whether the development of the CAR over adolescence differs by the persistence of aggression and rule-breaking. The results indicated that while

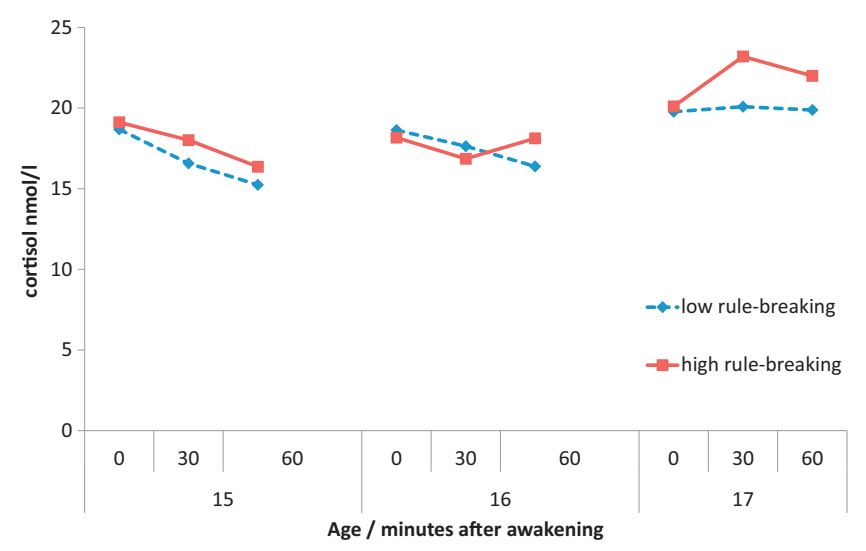

Fig. 3. Cortisol awakening response over adolescence for trajectories of high and low rule-breaking. high aggressive adolescents consistently showed decreased awakening cortisol levels, high rule-breaking adolescents' CARs were similar to low rule-breaking adolescents' CARs. This indicates that neurobiological correlates may depend on the type and persistence of antisocial behavior investigated. The development of the CAR over the years, did not differ between the high and low aggressive or rule-breaking adolescents.

The differential development of the CAR by type of antisocial behavior, corroborates the hypothesis that aggression and rulebreaking have different underlying mechanisms (Burt, 2012). Burt (2012) argues that aggression is more stable within individuals (Broidy et al., 2003), and to a larger extent genetically influenced (Burt, 2012) than rule-breaking. Rule-breaking on the other hand, is mostly influenced by social and contextual factors, such as delinquent peers and social economic factors (Dishion and Dodge, 2005; Pare, 2006). The current results add that this often used stress-related risk factor for antisocial behavior, decreased HPA axis activity, may be specific for aggression. It has been suggested that earlier reports of associations between rule-breaking and HPA axis activity could be indirect via overlap with aggressive behavior (McBurnett et al., 2000). As aggression and rule-breaking are largely overlapping behaviors within individuals (Loeber and Schmaling, 1985), this may account for the discrepancy between the current results and a previous study reporting consistently low cortisol in relation to risky behavior (Shirtcliff et al., 2005). Risky behavior, as assessed in their study, mostly resembles rulebreaking, yet also incorporates aggressive items such as getting into fights. In summary, aggression can best be described as a personal characteristic (Olweus, 1979), whereas rule-breaking is better described as behavior driven by exogenous factors. Although these results add to the increasing evidence of different mechanisms behind aggression and rule-breaking, more fundamental research is warranted to elucidate the possible different etiologies.

Moreover, decreased cortisol may be specific for persistent trajectories of aggression. These longitudinal associations of consistently decreased awakening cortisol levels in persistent aggressive adolescents, are in accordance with findings in a previous 
longitudinal study in preadolescent boys (McBurnett et al., 2000). Although their small sample size precluded formal longitudinal analysis (i.e. examining persistence of aggression and consistency of cortisol concurrently) their results do show that persistent aggression is associated with low cortisol, as well as that those with consistent low cortisol show the most aggression and an early-onset of aggression. Moreover, another study in preadolescent boys and girls indicated that low cortisol in preadolescence did not predict antisocial behavior 2 years later for the whole sample, but only persistent antisocial behavior in those already showing behavior problems in preadolescence (Sondeijker et al., 2008). Previous cross-sectional studies in adolescents in contrast, have more difficulty assessing persistent aggression, and yielded inconsistent results on the relation between aggression and cortisol (Pajer et al., 2001; Scerbo and Kolko, 1994; van Bokhoven et al., 2005). In line with this reasoning, aggression in adults is also associated with decreased cortisol levels (Virkkunen, 1985). In adults aggression is even less prevalent, yet those who are aggressive are likely to have been aggressive persistently throughout their life-span (Lahey et al., 2003). Decreased cortisol levels may even be predictive of persistent aggression (Shoal et al., 2003), yet on the basis of the current results, such causal inferences could not be made. Although this longitudinal study is the first to relate persistent aggression to consistent decreased cortisol over adolescence, longitudinal studies starting early in childhood are warranted in order to investigate the predictive value of cortisol for persistent aggression.

The CAR is seen as a stable trait characteristic (Edwards et al., 2001), suitable as a biological marker for individual HPA axis activity (Pruessner et al., 1997). In addition to basal activity of the HPA axis, the rise in cortisol levels as a response to awakening reflects the reactivity or flexibility of the HPA axis (Fries et al., 2009). With adolescence, the response to awakening has been shown to develop, whereas cortisol levels at awakening remain stable (Platje et al., 2013). These stable cortisol levels at awakening appeared to be consistently decreased in persistent aggressive adolescents. The results did not support the hypothesis that persistent aggressive adolescents would not show the development of the cortisol response to awakening over adolescence. However, as there exists large variation in the development of the CAR, in the current study the persistent aggressive sample may be too small to detect differences with low aggressive adolescents. Studies in larger samples, as well as comparing more homogeneous and extreme groups (e.g. clinic-referred aggressive adolescents with normal controls), should be performed to provide more insight in potential developmental differences in the CAR.

There are some methodological limitations of the study that should be noted. First, each year, saliva was sampled on one day only, correcting for day-to-day variation was therefore not possible. Previous studies have however already shown that day-to-day variation of the CAR is low (Edwards et al., 2001; Wust et al., 2000). Second, saliva sampling was done at home. Although we took all possible precautions in the sampling procedure, among which self-report of exact sampling times, directly monitoring participant's compliance was not possible. However, sampling of the CAR at home, was previously found not to differ from sampling at a controlled laboratory environment (Wilhelm et al., 2007). Selfreported sampling times have even been found to be preferable to automatic time recording (Kraemer et al., 2006). Third, antisocial behavior was only determined from self-report. Parent-reported antisocial behavior may have resulted in different outcomes. However, in adolescence, youths spend less and less time at home with their parents, and especially antisocial behavior all too often remains unnoticed to others. In adolescence therefore, self-report is expected to give an accurate view of antisocial behavior. Fourth, information on medication use and menstrual phase was unavailable, and could not be controlled for in the analyses. However, psychostimulantia use, most frequently associated with antisocial behavior, has previously been reported not to be associated with differences in salivary cortisol in the morning, or in the diurnal rhythm (Hibel et al., 2007). Menstrual phase as well, has previously been shown not to affect the CAR (Kirschbaum et al., 1999; Kudielka and Kirschbaum, 2003).

Despite these limitations, the current results may have important implications for future research. This is the first study to investigate the development of HPA axis activity by type and persistence of antisocial behavior. As the findings indicate that decreased HPA axis activity may be specific for persistent aggression, most antisocial behavior in adolescents could be unrelated to neurobiological parameters. Future studies on HPA axis activity may therefore benefit from distinguishing aggression and rule-breaking, thereby also furthering the knowledge on the underlying mechanisms of these behaviors. As aggression covers a wide spectrum of behavior, and decreased HPA axis activity may be related more strongly to, e.g. proactive as compared to reactive aggression (Lopez et al., 2004), it is important for future studies to further differentiate aggressive behavior. Moreover, our new approach revealed that, despite all the change and development in adolescence, persistent aggressive adolescents showed decreased cortisol levels consistently over time. This is an important prerequisite for the prediction of persistent aggression. Further research covering the development from child to adulthood is therefore warranted, in order to examine to what extend consistently decreased cortisol earlier in life may predict persistent aggression.

\section{Role of the funding source}

The RADAR study has been financially supported by main grants from the Netherlands Organization for Scientific Research (GB-MAGW 480-03-005, GB-MAGW 480-08-006, GB-MAGW 40005-212), and Stichting Achmea Slachtoffer en Samenleving (SASS), and various other grants from the Netherlands Organization for Scientific Research, the VU University Amsterdam and Utrecht University. This project has been supported by the Foundation "De Drie Lichten" in the Netherlands. The funding sources had no further role in study design, collection, analysis and interpretation of data, nor in the writing of the manuscript or in the decision to submit the paper for publication.

\section{Conflicts of interest}

All the authors have no biomedical financial interests or potential conflicts of interest to report.

\section{Acknowledgements}

Data from the RADAR study were used. RADAR has been financially supported by main grants from the Netherlands Organization for Scientific Research, Stichting Achmea Slachtoffer en Samenleving (SASS), and the VU University Amsterdam and Utrecht University. This project has been supported by the Foundation "De Drie Lichten" in the Netherlands. We sincerely thank all participating families and schools for taking part in this study.

\section{References}

Achenbach, T.M., 1991a. Manual for the Teachers Report Form and 1991 Profile. University of Vermont, Department of Psychiatry, Burlington, VT.

Achenbach, T.M., 1991b. Manual for the Youth Self-Report and 1991 Profile. University of Vermont, Department of Psychiatry, Burlington, VT.

Achenbach, T.M., Conners, C.K., Quay, H.C., Verhulst, F.C., Howell, C.T., 1989. Replication of empirically derived syndromes as a basis for taxonomy of child/adolescent psychopathology. Journal of Abnormal Child Psychology 17, 299-323. 
Alink, L.R.A., van Ijzendoorn, M.H., Bakermans-Kranenburg, M.J., Mesman, J., Juffer, F., Koot, H.M., 2008. Cortisol and externalizing behavior in children and adolescents: mixed meta-analytic evidence for the inverse relation of basal cortisol and cortisol reactivity with externalizing behavior. Developmental Psychobiology $50,427-450$

Bollen, K., 1989. Structural Equation Modeling with Latent Variables. Wiley, New York.

Broidy, L.M., Nagin, D.S., Tremblay, R.E., Bates, J.E., Brame, B., Dodge, K.A., Fergusson, D., Horwood, J.L., Loeber, R., Laird, R., Lynam, D.R., Moffitt, T.E., Pettit, G.S., Vitaro, F., 2003. Developmental trajectories of childhood disruptive behaviors and adolescent delinquency: a six-site, cross-national study. Developmental Psychology 39, 222-245.

Burt, S.A., 2012. How do we optimally conceptualize the heterogeneity within antisocial behavior? An argument for aggressive versus non-aggressive behavioral dimensions. Clinical Psychology Review 32, 263-279.

Dishion, T.J., Dodge, K.A., 2005. Peer contagion in interventions for children and adolescents: moving towards an understanding of the ecology and dynamics of change. Journal of Abnormal Child Psychology 33, 395-400.

Edwards, S., Clow, A., Evans, P., Hucklebridge, F., 2001. Exploration of the awakening cortisol response in relation to diurnal cortisol secretory activity. Life Sciences 68, 2093-2103.

Fries, E., Dettenborn, L., Kirschbaum, C., 2009. The cortisol awakening response (CAR): facts and future directions. International Journal of Psychophysiology $72,67-73$.

Gunnar, M.R., Vazquez, D., 2006. Stress neurobiology and developmental psychopathology. In: Cicchetti, D., Cohen, D.J. (Eds.), Developmental Psychopathology: Developmental Neuroscience. John Wiley \& Sons, Hoboken, NJ.

Hibel, L.C., Granger, D.A., Cicchetti, D., Rogosch, F., 2007. Salivary biomarker levels and diurnal variation: associations with medications prescribed to control children's problem behavior. Child Development 78, 927-937.

Kiess, W. Meidert, A., Dressendorfer, R.A. Schriever, K., Kessler, U., Konig, A. Schwarz, H.P., Strasburger, C.J., 1995. Salivary cortisol levels throughout childhood and adolescence: relation with age, pubertal stage, and weight. Pediatric Research 37, 502-506.

King, R.J., Jones, J., Scheuer, J.W., Curtis, D., Zarcone, V.P., 1990. Plasma cortisol correlates of impulsivity and substance abuse. Personality and Individual Differences 11, 287-291.

Kirschbaum, C., Kudielka, B.M., Gaab, J., Schommer, N.C., Hellhammer, D.H., 1999. Impact of gender, menstrual cycle phase, and oral contraceptives on the activity of the hypothalamus-pituitary-adrenal axis. Psychosomatic Medicine 61, $154-162$.

Kline, R.B., 2005. Principles and Practice of Structural Equation Modeling, 2nd ed. The Guildford Press, New York, NY.

Kraemer, H.C., Giese-Davis, J., Yutsis, M., O’Hara, R., Neri, E., Gallagher-Thompson, D., Taylor, C.B., Spiegel, D., 2006. Design decisions to optimize reliability of daytime cortisol slopes in an older population. American Journal of Geriatric Psychiatry $14,325-333$

Kudielka, B.M., Kirschbaum, C., 2003. Awakening cortisol responses are influenced by health status and awakening time but not by menstrual cycle phase. Psychoneuroendocrinology 28, 35-47.

Lahey, B., Moffitt, T.E., Caspi, A., 2003. The Causes of Conduct Disorder and Serious Juvenile Delinquency. Guilford, New York.

Little, R.J.A., 1988. A test of missing completely at random for multivariate data with missing values. Journal of the American Statistical Association 83, 1198-1202.

Loeber, R., Schmaling, K.B., 1985. Empirical evidence for overt and covert patterns of antisocial conduct problems: a metaanalysis. Journal of Abnormal Child Psychology 13, 337-353.

Lopez, N.L., Vazquez, D.M., Olson, S.L., 2004. An integrative approach to the neurophysiological substrates of social withdrawal and aggression. Development and Psychopathology 16, 69-93.

McBurnett, K., Lahey, B.B., Rathouz, P.J., Loeber, R., 2000. Low salivary cortisol and persistent aggression in boys referred for disruptive behavior. Archives of General Psychiatry 57, 38-43.

Moffitt, T.E., 1993. Adolescence-limited and life-course-persistent antisocial behavior: a developmental taxonomy. Psychological Review 100, 674-701.

Monshouwer, K., Verdurmen, J., Van Dorsselaer, S., Smit, E., Gorter, A., Vollebergh, W., 2008. Youth, Risky, Behaviour. Core Data, 2007: Smoking, Drinking, Drug Use, Gambling in Pupils over 10 Years, Old (Jeugd en riskant gedrag 2007: kerngegevens uit het Peilstationsonderzoek scholieren: roken, drinken, drugsgebruik en gokken onder scholieren vanaf tien jaar). Trimbos-instituut, Utrecht, the Netherlands.

Muthén, L.K., Muthén, B.O., 2007. Mplus User’s Guide, 4th ed. Muthén \& Muthén, Los Angeles.

Nagin, D.S., 2005. Group Based Modeling of Development. Harvard University Press, Cambridge, MA.
Olweus, D., 1979. Stability of aggressive reaction patterns in males: a review. Psychological Bulletin 86, 852-857.

Pajer, K., Gardner, W., Rubin, R.T., Perel, J., Neal, S., 2001. Decreased cortisol levels in adolescent girls with conduct disorder. Archives of General Psychiatry 58, 297-302.

Pare, P.P., 2006. Income inequality and crime across nations reexamined. (Doctoral dissertation). Pennsylvania State University, University Park, ProQuest.

Petersen, A.C., Crockett, L., Richards, M., Boxer, A., 1988. A self-report measure of pubertal status: reliability, validity, and initial norms. Journal of Youth and Adolescence 17, 117-133.

Platje, E., Vermeiren, R.R.J.M., Branje, S.J.T., Doreleijers, T.A.H., Meeus, W.H.J., Koot, H.M., Frijns, T., Van Lier, P.A.C., Jansen, L.M.C., 2013. Long-term stability of the cortisol awakening response over adolescence. Psychoneuroendocrinology 38, 271-280.

Popma, A., Doreleijers, T.A.H., Jansen, L.M.C., van Goozen, S.H.M., van Engeland, H., Vermeiren, R., 2007. The diurnal cortisol cycle in delinquent male adolescents and normal controls. Neuropsychopharmacology 32, 1622-1628.

Pruessner, J.C., Wolf, O.T., Hellhammer, D.H., Buske-Kirschbaum, A., von Auer, K. Jobst, S., Kaspers, F., Kirschbaum, C., 1997. Free cortisol levels after awakening: a reliable biological marker for the assessment of adrenocortical activity. Life Sciences 61, 2539-2549.

Raine, A., Moffitt, T.E., Caspi, A., Loeber, R., Stouthamer-Loeber, M., Lynam, D., 2005. Neurocognitive impairments in boys on the life-course persistent antisocial path. Journal of Abnormal Psychology 114, 38-49.

Rosmalen, J.G.M., Oldehinkel, A.J., Ormel, J., de Winter, A.F. Buitelaar, J.K., Verhulst, F.C., 2005. Determinants of salivary cortisol levels in 10-12 year old children: a population-based study of individual differences. Psychoneuroendocrinology 30, 483-495.

Satorra, A., Bentler, P.M., 1994. Corrections to test statistics and standard errors in covariance structure analysis. In: von Eye, A., Clogg, C.C. (Eds.), Latent Variable Analysis: Applications for Developmental Research. Sage Publishers, Thousand Oaks, CA, pp. 399-419.

Scerbo, A.S., Kolko, D.J., 1994. Salivary testosterone and cortisol in disruptive children: relationship to aggressive, hyperactive, and internalizing behaviors. Journal of the American Academy of Child and Adolescent Psychiatry 33, 1174-1184.

Shirtcliff, E.A., Granger, D.A., Booth, A., Johnson, D., 2005. Low salivary cortisol levels and externalizing behavior problems in youth. Development and Psychopathology $17,167-184$.

Shoal, G.D., Giancola, P.R., Kirillova, G.P., 2003. Salivary cortisol, personality, and aggressive behavior in adolescent boys: a 5-year longitudinal study. Journal of the American Academy of Child and Adolescent Psychiatry 42, 1101-1107.

Sondeijker, F.E., Ferdinand, R.F., Oldehinkel, A.J., Tiemeier, H., Ormel, J., Verhulst, F.C., 2008. HPA-axis activity as a predictor of future disruptive behaviors in young adolescents. Psychophysiology 45, 398-404.

Sondeijker, F.E., Ferdinand, R.F., Oldehinkel, A.J., Veenstra, R., Tiemeier, H., Ormel, J., Verhulst, F.C., 2007. Disruptive behaviors and HPA-axis activity in young adolescent boys and girls from the general population. Journal of Psychiatric Research $41,570-578$.

Stadler, C., Poustka, F., Sterzer, P., 2010. The heterogeneity of disruptive behavior disorders - implications for neurobiological research and treatment. Front Psychiatry 1, 21.

Tremblay, R.E., 2010. Developmental origins of disruptive behaviour problems: the original sin hypothesis, epigenetics and their consequences for prevention. Journal of Child Psychology and Psychiatry 51, 341-367.

van Bokhoven, I., Van Goozen, S.H.M., Van Engeland, H., Schaal, B., Arseneault, L. Seguin, J.R., Nagin, D.S., Vitaro, F., Tremblay, R.E., 2005. Salivary cortisol and aggression in a population-based longitudinal study of adolescent males. Journa of Neural Transmission 112, 1083-1096.

van Goozen, S.H.M., Fairchild, G., Snoek, H., Harold, G.T., 2007. The evidence for a neurobiological model of childhood antisocial behavior. Psychological Bulletin $133,149-182$.

Verhulst, F.C., Van der Ende, J., Koot, J.M., 1997. Handleiding Voor de Youth Self-Report. Afdeling Kinder-en Jeugdpsychiatrie, Sophia Kinderziekenhuis/Academisch Ziekenhuis Rotterdam/Erasmus Universiteit Rotterdam, Rotterdam.

Virkkunen, M., 1985. Urinary free cortisol secretion in habitually violent offenders. Acta Psychiatrica Scandinavica 72, 40-44.

Wilhelm, I., Born, J., Kudielka, B.M., Schlotz, W., Wust, S., 2007. Is the cortisol awakening rise a response to awakening? Psychoneuroendocrinology 32, 358-366.

Woodman, D.D., Hinton, J.W., O'Neill, M.T., 1978. Cortisol secretion and stress in maximum security hospital patients. Journal of Psychosomatic Research 22, $133-136$.

Wust, S., Wolf, J., Hellhammer, D.H., Federenko, I., Schommer, N., Kirschbaum, C., 2000. The cortisol awakening response - normal values and confounds. Noise \& Health $2,79-88$. 